\title{
Features of using modified bitumen in road construction
}

\author{
Aigerim Syzdykova, (D)Aigul Zhakyp*, (D)Assel Tulebekova \\ Department of Structural Engineering, L.N. Gumilyov Eurasian National University, Nur-Sultan, Kazakhstan \\ *Correspondence: aigul.kairatkizi@mail.ru
}

\begin{abstract}
The road industry is one of the important components of the economy. Quantitative and qualitative changes in the road industry require new technological approaches to road construction. The higher the transport-operational level of roads, the less the negative consequences of motorization are manifested. The condition of highways and their compliance with the international standards largely depends on the observance of construction technologies of road pavement, and the road pavement itself should have layers of strong, frost and temperature resistant monolithic materials which provide a long period of exploitation. The paper presents the peculiarities of the application of different types of modifiers for bitumen. It discusses their advantages and disadvantages, the importance of selecting the composition of the bituminous and mineral mixture. The use of crumb rubber as a modifier allows to realize the concept of a closed resource-saving technology of construction of roads. This approach will allow, on a technologically sound basis and taking into account the real needs of road construction materials, to restore the road network.
\end{abstract}

Keywords: road, construction, bitumen, modify, method

\section{Introduction}

The productive work of road transport, the effective use of personal cars requires a developed network of landscaped roads. Therefore, the road industry faces the task of ensuring the competitiveness of the domestic transport and communication complex in the world market. In this regard, the quality of roads must meet international requirements. The main transport and operational indicators of the road: the strength of pavement and subgrade, smoothness and roughness of the road surface, tire traction with the road surface, wear resistance of the road surface, the serviceability of the pavement.

One of the promising ways to improve the quality of road to development, implementation in the practice of road construction of bitumen improved quality, based on new materials that can provide greater strength, durability of road surfaces, compared with the potential capabilities of petroleum bitumen. The application of high-quality binding materials, providing the prolongation of service life of road asphalt concrete pavement reduces the expenses for its repair and maintenance. In this regard, bitumen, as a gross product produced on a large scale, serves as the basis. The required level of quality, which determines the performance characteristics of asphalt concretes, is achieved by the introduction of various modifying components.

Bitumen perfectly resists the influence of various chemical reagents, is waterproof and gas-proof, resistant to different types of radiation and prolonged thermal influence [1-3]. It is these valuable qualities of bitumen combined with low cost and mass production have made them indispensable in many industries. Most of the existing methods of bitumen analysis are based on the difference in solubility of their components in a number of organic solvents. The methods of structure-group analysis, although with significant assumptions, give an idea of the averaged structure of bitumen substance molecules or its components. The first of such methods was the n-d-M method developed by Tadema for oils [4]. Subsequently, it was developed by Van Krevelen in a densimetric graphical method for structural analysis of coals and later found its development in a number of researchers [5]. 
There are also many other methods of analysis, which serve to study the composition of bitumen. For example, reverse and pyrolytic chromatography [6], mass spectroscopy.

When modifying bitumen [7-8], the following modifiers are distinguished: adhesion, diluting, plasticizing, structuring-plasticizing, adhesion-structuring, structuring, stabilizing, emulsifiers (Figure $1)$.

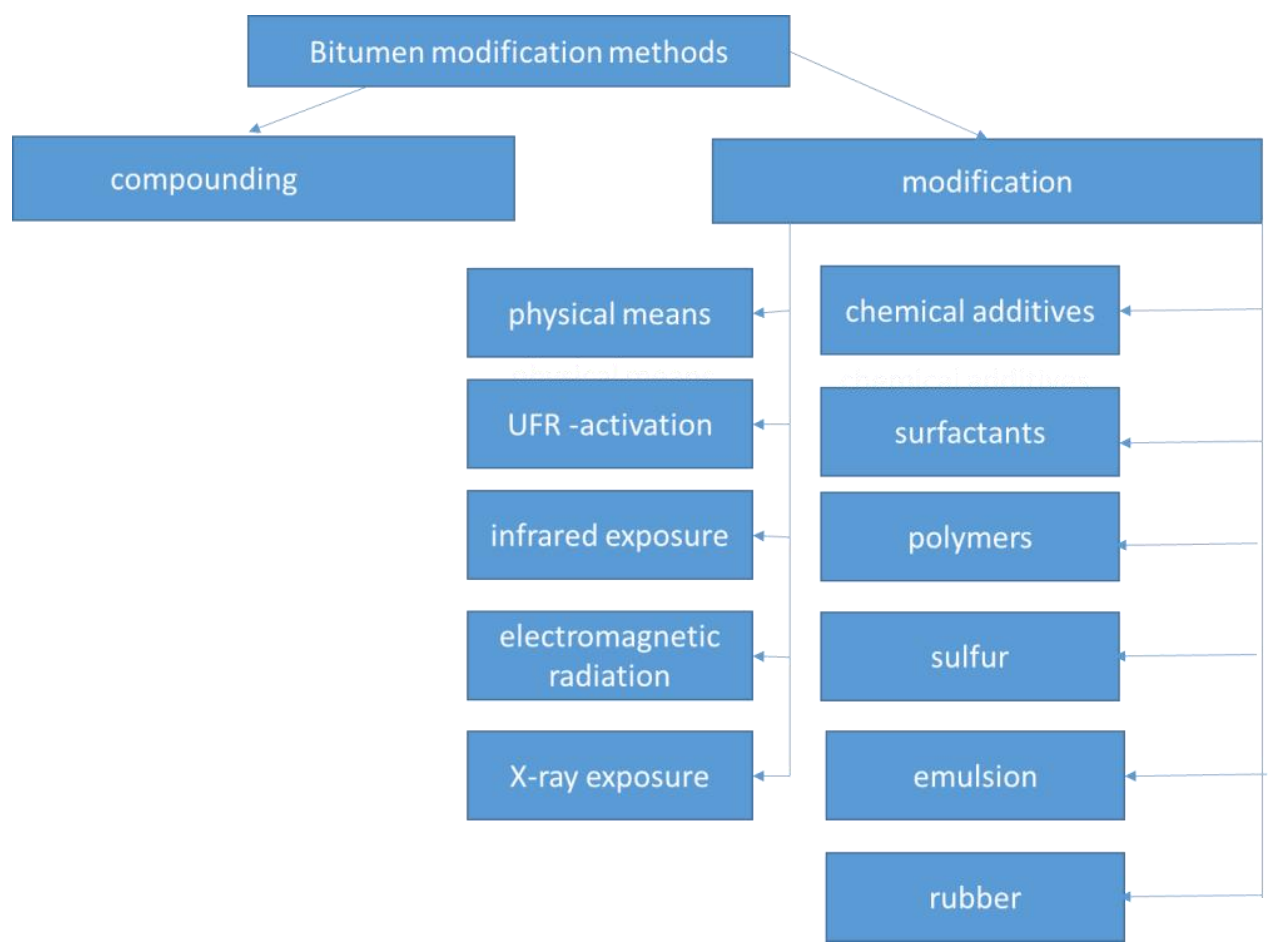

Figure 1 - Bitumen modification methods

Additives of adhesive nature are most widely used in the production of asphalt concrete [3-9]. The introduction of such additives can improve the wetting conditions of the bitumen surface of mineral materials, forming an absorption layer, facing the polar groups to the surface of the mineral material and the hydrocarbon part in the bitumen volume. This reduces the temperature and time to obtain a homogeneous mixture, and also significantly reduces the intensity of aging processes of bitumen. Also by using the surfactant at the interface of the mineral material-bitumen can form a monomolecular chemisorption layer that promotes the formation of a strong bond between them.

In the study of influence of sulfur additives on the performance properties of bitumen Eigenson and Fryazinov [10] observed the increase of expandability of bitumen produced by cracking of residues of high-paraffin oils, when treated with 1-10\% sulfur. Improvement of properties of road bitumen can be achieved by the introduction of sulfur at temperatures from 110 to $170^{\circ}$. In order to improve durability of road bitumen Kikichi Eiichi offers additives of calcium sulfonate-sulfur compounds.

Generalizations of foreign experience in sulfur application for road construction were made by [11] and allowed to distinguish three directions of sulfur application:

- the introduction of sulfur into bitumen in relatively small quantities (up to 20\%) to produce sulfur-bitumen binder in asphalt concrete production;

- introducing sulfur into bitumen in relatively large quantities (over 20\%) shows itself as a kind of active filler in the binder;

- plasticization of sulfur with organic plasticizers with complete replacement of bitumen.

Sulfur acts similarly on high-molecular-weight hydrocarbons of oil fraction selenium. When oil is heated with selenium, selenohydrogen is released. At the same time with increasing temperature oil gradually transforms into a solid asphalt-like mass. It has been noted that more than $1 \%$ of selenium is chemically bound to the oil. Chlorine passing through bitumen layer causes dehydrogenation and polymerization reaction. Some of the chlorine binds with the compounds in the bitumen to form 
chlorinated organic compounds, and some is released as hydrogen chloride. Some researchers point out the higher activity of the most aromatized asphaltene part of bitumen in relation to chlorine.

Repeatedly emphasized in works [2] that the main disadvantage of asphalt concrete mixtures is a large consumption of bitumen and suggested to reduce the bitumen content in asphalt concrete mixtures by $40-50 \%$. This led to obtaining asphalt concrete with porosity more than $10 \%$. Also derived the factors that ensure the reduction of bitumen consumption:

- rational selection of the grain composition of the mineral part in order to provide a certain density of the mineral skeleton and framework monolith;

- mandatory content of mineral powder to increase the cohesion of bitumen, improve the adhesion of bitumen to the surface of mineral grains and partial filling of intergranular pores;

- reduction of the total specific surface of the mineral part by increasing the content of crushed stone, which reduces the consumption of bitumen to envelope the grains, to provide water resistance due to thicker films of bitumen on the mineral grains;

- maximum compaction of the substrate.

\section{Methods and materials}

Pavement is a multilayered structure that is designed to redistribute the pressure on the ground from the action of traffic loads and to ensure an increase in the service life and transport performance of highways. Pavement includes the following layers: pavement, subgrade and subgrade. Figure 2 shows the structural layers of road pavements [12].

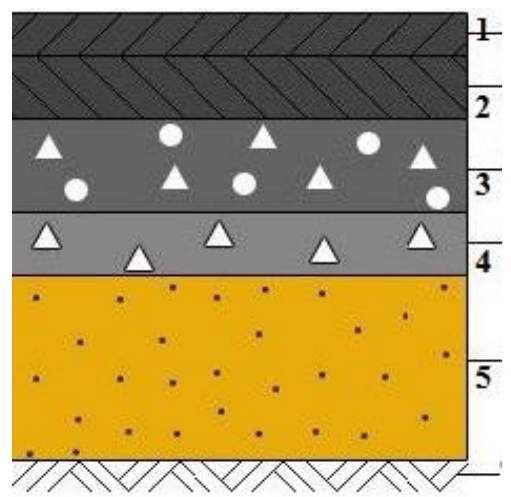

Figure 2 - Constructive layers of roadways: 1 - top layer of asphalt; 2 - base or bottom layer of asphalt; 3 - rolling concrete; 4 - crushed stone; 5 - sand [13]

For the use of innovative resource-saving road-building materials, the following measures are proposed:

- reuse man-made industrial materials;

- introduce new complex binders for road asphalt concrete;

- to monitor their effectiveness;

- introduce the needs accounting;

- create production bases for the development of innovative materials for road construction;

- use on pilot sites.

The problem of worn out automobile tires and out-of-use rubber products is of great environmental and economic importance. The greatest potential for improving the properties of bituminous binders, has the crumb from general purpose rubber, including tire rubber. In this case, the problem with raw materials is completely removed. Compared with the use of expensive modifiers based on synthetic rubbers and elastomers, crumb rubber is a much cheaper product, which also makes the new technology one of the most economical ways to improve the properties of road bitumen [14]. 
Rubber is much more resistant to the oxidizing effects of air oxygen than rubber. It is highly resistant to water and salt solutions. In addition, an important feature of rubber crumb, especially tire crumb, is the presence in its composition of special chemicals-antioxidants and antioxidants [14]. Their presence can provide increased resistance of the binder to oxidative degradation in operating conditions. Slow down the aging processes at operating temperatures and under operating conditions. Will slow down the aging processes at operating temperatures and under conditions of warming to a high technological temperature. In the rubber separation module, rubber pieces 100-150 mm in size enter the pelletizer (Figure 2), where they are crushed to $10-15 \mathrm{~mm}$, separation of metal and partially textile cord. Free metal is removed by magnetic separators, and the textile cord by textile removal system. The crumb rubber cleaned from the metal cord goes to the storage hopper.The processing technology is based on mechanical shredding of tires into small pieces with subsequent mechanical separation of metal and textile cords and obtaining rubber "granulate" with a size from $0.5 \mathrm{~mm}$ to 5.0 $\mathrm{mm}$ by shear shredding. The technological scheme of the fine grinding unit is shown in the Figure 3 .
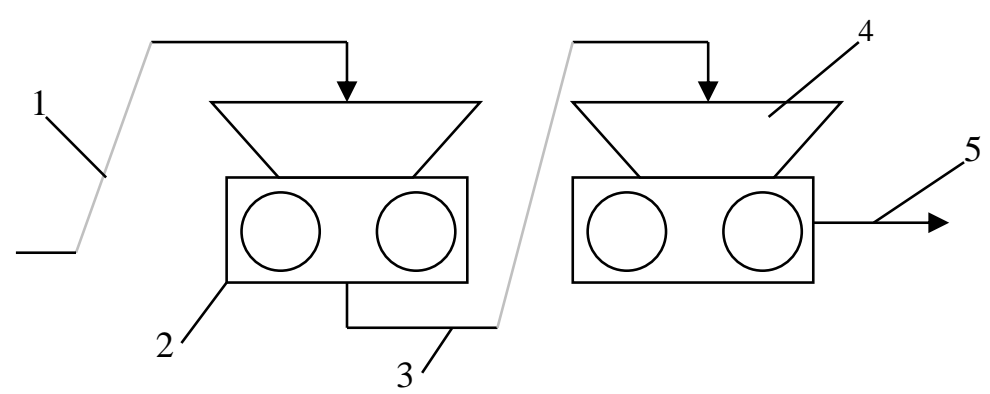

Figure 3 - Technological scheme of the rubber shredding module: 1, 3, 5 - belt conveyors; 2 double-rotor knife crusher 1; 4 - double-rotor knife crusher 2

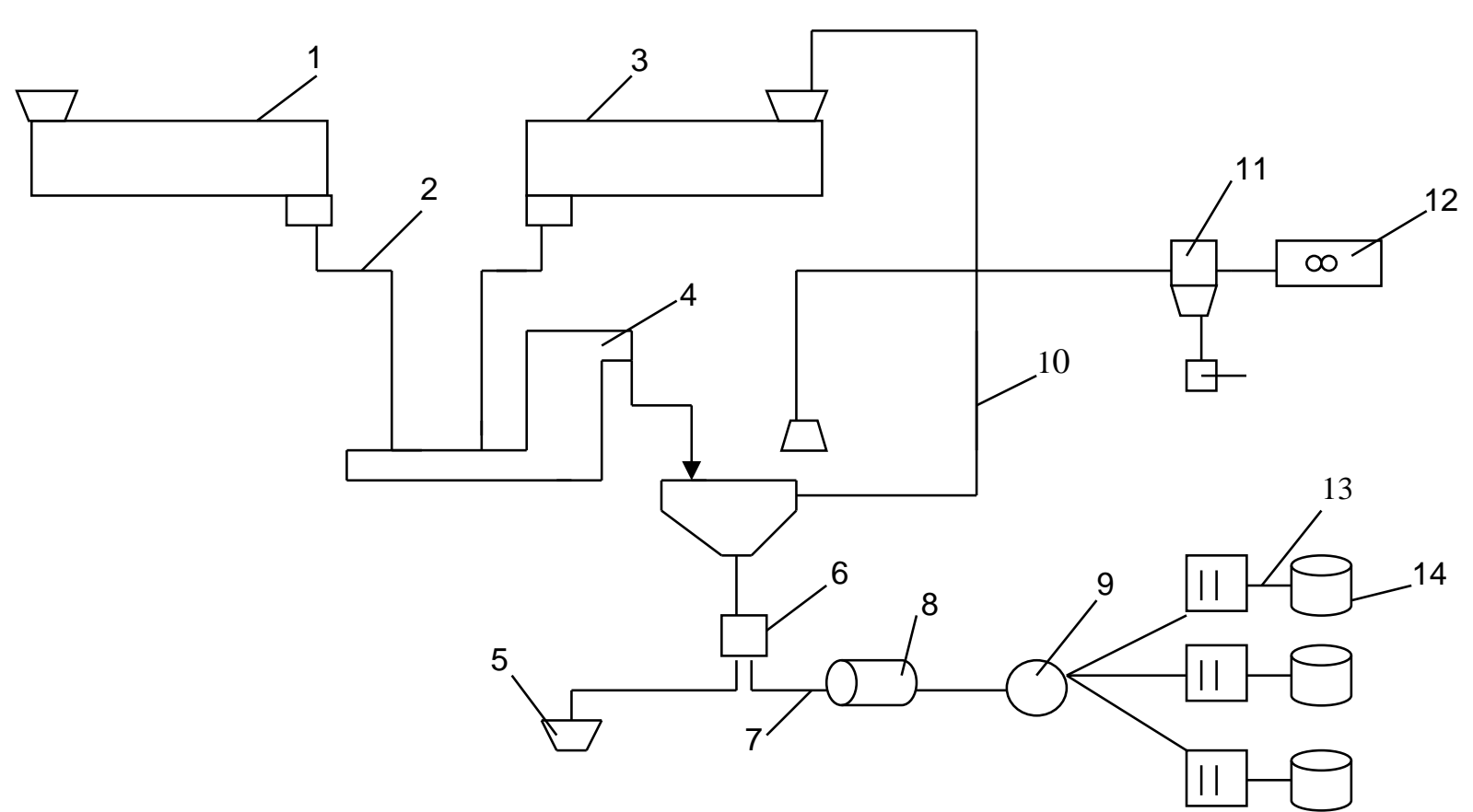

Figure 4 - Technological scheme of the fine grinding unit: 1 - grinder of coarse grinding; 2, 7 , 10, 13 - conveyors; 3 - fine grinding grinder; 4 - cooler conveyor; 5, 6- magnetic separator, 8 - fine grinder; 9 - vibrating screen; 11 - cyclone; 12 - fan; 14 - fulfilment racks

The study [15] proposed the use of waste packaging "Tetra Pak", the use of which provides durability and increase the brightness of the color of asphalt concrete pavement. The properties of the secondary polymer, which includes aluminum foil particles, provide protection of the polymer 
component from premature aging associated with photochemical degradation. Tetra Pak" packaging consists of the following elements shown in Figure 5:

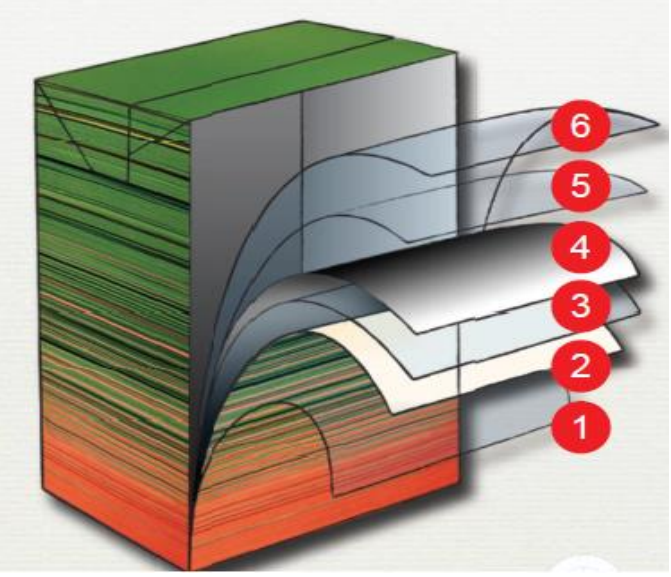

Figure 5 - Tetra Pak packaging elements: 1 - outer layer of polyethylene; 2 - cardboard backing; 3 polyethylene layer; 4 - aluminum foil; 5 - one bonding layer of polyethylene; 6 - special polyethylene layer [16]

The technological process for the preparation of the mixture for the road bed includes the following basic operations [17]:

- preparation of mineral materials (supply and pre-dosing, drying and heating to the desired temperature, fractional dosing);

- feeding of cold mineral powder and stabilizing additive, their dosing before introduction to the mixer;

- bitumen preparation (heating and fed, if necessary, from the bitumen storage to the asphalt melting plant, evaporating the moisture contained in it and heating to a working temperature, if necessary, the introduction of surfactants and other improving additives, dosing before fed into the mixer's mixer);

- "Dry" mixing of hot mineral materials with cold mineral powder and modifying additive

- mixing of mineral materials with bitumen and unloading of the prepared asphalt-concrete mixture into the storage bin or dump trucks.

The addition of polymers in terms of the possibility of increasing the operational properties of the pavement, namely, expanding the operating temperature range of the bituminous binder. This polymer increases the resistance of roads to both rutting in summer and cracking in winter. This property is especially valuable in climatic conditions, where due to significant seasonal temperature fluctuations conventional bitumen without additives often cannot ensure the durability of the pavement.

According to the classification, the experimental site to be built, is located in the built-up part of Nur-Sultan, confined to the right bank above the floodplain valley of the river Ishim.

The street is an important planning axis of the city in the direction north - south, providing transport links right bank of the city with the main highways' districts, overlooking the bridges over the river Ishim to the new administrative center of the capital on the left bank.

In the geological area involved: middle to Upper Quaternary deposits of clayey deluvial proglovial formations uncovered by all wells to a depth of $0.8-4.5 \mathrm{~m}$; weathering crust formation on siltstones uncovered by separate wells to a depth of 0.8 to $4.5 \mathrm{~m}$; from the surface the sediment overlaps the soil-vegetation layer.

Ground waters at the area to be constructed are uncovered by the wells №3.5-13 at the depth of 0.9 to $2.2 \mathrm{~m}$, are confined to the sandy interlayers of clay formations. Established level of groundwater in all wells from 0.75 to $2.0 \mathrm{~m}$.

Within the existing carriageway right-of-way, there is a temporary $0.2-0.36$-thick pavement, represented by artificially compacted timber soil. 
Soils, within the spread of the active zone of the working layer (to a depth of $1.5 \mathrm{~m}$ ), throughout the road to be built are porous.

Under the normative location of ground waters do not affect and moistening of soils of the working layer in the pre-frost period:

- in loams light, sandy, dusty $184+150=334 \mathrm{~cm}$;

- in sandy loam $225+100=325 \mathrm{~cm}$;

- in clays, heavy loams $184+200=384 \mathrm{~cm}[39]$.

Ground waters are moderately saline, salinity $3191 \mathrm{mg} / \mathrm{dm}^{3}$. According to salt composition, they are sulfate-chloride and sodium-depth, have carbonic acid aggression to concrete of $\mathrm{W} 4$ grade, medium to reinforcement of reinforced concrete structure at periodic wetting.

The pavement is designed with asphalt-concrete surface on cement-concrete base. The thickness of layers is calculated taking into account the category of the street, perspective intensity of traffic, the service life of the construction of hydrological and construction properties of the underlying soils, the availability of local road-building materials. Rubber crumb was used as a bitumen modifier.

Experimental study of bituminous composition presented in Table 1.

Table 1 - The bituminous composition

\begin{tabular}{ccc}
\hline Incoming Components & Quantity, kg & Composition \\
\hline Bitumen 90/130 & 350 & Bitumen 90/130 \\
\hline H2SO4 & 15 & H2SO4 \\
\hline Surfactant oxyethylated alkylphenol & 5 & Surfactant oxyethylated alkylphenol \\
\hline Mineral powder fraction $0.07 \mathrm{~mm}$ & 25 & Mineral powder fraction $0.07 \mathrm{~mm}$ \\
\hline Rubber crumb (tire) fraction $0.5 \mathrm{~mm}$ & 25 & Rubber crumb (tire) fraction $0.5 \mathrm{~mm}$ \\
\hline
\end{tabular}

Technology of preparation of the composition includes the following procedures: oil bitumen is raised to a temperature of $180^{\circ} \mathrm{C}$, then a solution of sulfo-oxidizer, which can be sulfuric acid $\mathrm{H} 2 \mathrm{SO} 4$, is introduced in portions discretely or using a dispenser calibrated to the flow per unit time for 20 minutes and stirred, after stopping the acid, then the surfactant - oxyethylated alkylphenol R-C6H4O$(\mathrm{CH} 2 \mathrm{CH} 2) n-\mathrm{CH} 2 \mathrm{CH} 2 \mathrm{OH}$ is introduced into the mixture and blended for 10 minutes at $180{ }^{\circ} \mathrm{C}$. Then mineral powder and rubber granules are introduced in portions and blended for 45 minutes until complete distribution and homogeneity.

Organic binders used in road construction must have a set of properties that ensure high quality and standard service life of pavements and foundations built on the basis of these binders [18]:

- strong adhesion to the surface of mineral materials - water resistance and frost resistance of asphalt concrete;

- plasticity at low temperatures - cracking resistance of pavement in winter time;

- strength and heat resistance at high temperatures - shear stability of pavement in hot summer days;

- resistance to aging (preservation of properties in time) during technological processing (evaporation, heating, mixing with mineral materials) and during operation.

Comparative performance of modified bitumen is shown in the Table 2 .

Table 2 - Comparison of the characteristics of bitumen binder samples

\begin{tabular}{ccc}
\hline Property values & \multicolumn{2}{c}{ Values of indicators of binder samples } \\
\hline & Bitumen $90 / 130$ & Bitumen $90 / 130$ with rubber crumb \\
\hline Needle penetration depth & & \\
$25^{\circ} \mathrm{C}$ & 100 & 100 \\
$0^{\circ} \mathrm{C}$ & 28 & 28 \\
\hline Plasticity interval, ${ }^{\circ} \mathrm{C}$ & 69 & 81 \\
\hline Stretch ability at $0^{\circ} \mathrm{C}, \mathrm{cm}$ & 3.5 & 6 \\
\hline
\end{tabular}




\section{Results and Discussion}

By creating in the mixture of bitumen and crumb rubber the conditions for specific step polymerization in the mode of "live" chains, the rubber particles, which absorbed a part of the maltene fraction of bitumen, are combined both between themselves and with high-molecular bitumen components in a heterogeneous, reinforcing, polymeric spatial structure by chemical bonds. Due to this structure, the binder becomes elastic enough for operational purposes. The stability of the entire dispersed heterogeneous system and the high and long-term adhesion of the binder are ensured by polar molecular groups introduced in large quantities into the chemical structure of the material during its preparation [14]. On the one hand, these groups increase the polarity of asphaltenes, which stabilizes the heterogeneous structure of the binder; on the other hand, they sharply increase the density of intermolecular (associative) bonds, which in this case are responsible for the adhesion of the material. Adhesion properties are inherent to the material itself of the composite rubber-bitumen binder. The rubber is also resistant to the oxidizing effects of air oxygen. It is highly resistant to water and salt solutions. In addition, an important feature of the rubber crumb, especially tire, is the presence in its composition of special chemicals - antioxidants and antistatic agents. Their presence can provide increased resistance of the binder to oxidative degradation in service conditions. It will slow down the aging processes at operating temperatures and under conditions of heating to high technological temperature.

Chemical substances involved in the polymerization process can create conditions under which it is possible to almost completely localize mobile unpaired conductivity electrons in colloidal bitumen particles and achieve their stabilization.

Coagulation and precipitation of crystals of the asphaltene fraction and carbonaceous graphitelike formations during aging in this case is kinetically and spherically difficult and practically does not occur. As well as gelation, which often happens during bitumen modification with rubbers and elastomers of SBS type, when the equilibrium and stability of colloidal state is broken because of the competition of polar molecules of asphaltenes and polymer in relation to the liquid dispersion phase. Rubber does not decompose and dissolve, but binds to the bitumen components by strong, but quite mobile chemical bonds.

\section{Conclusions}

In the interaction of bitumen and additives with high positive potential and a large number of adsorption centers in the form of cations an intensive transfer of bitumen from the bulk state to the state of diffusion-solvation shells occurs. During this structuring relatively strong physical and chemisorption bonds are formed, which firmly hold bitumen films on the surface of the additive particles.

When combining bitumen with additives, a microstructure is formed, which reflects the quantitative ratio, location and interaction of the binder and the most active component of bitumen. As shown by the study of methods of preparation of bitumens with polymer modifiers provide, as a rule, increased process temperature and intensive mixing of components. Bitumens soften when heated, and thermoplastic polymers, regardless of whether they are crystalline or amorphous, go into a viscous state. The use of modifiers solves the problem of using recycled construction materials and industrial waste.

\section{References}

1. Production of petroleum bitumen / Gureev A.A., Chernysheva Ye.A., Konovalov A.A., Kozhevnikova Yu.V.2007. $-102 \mathrm{p}$.

2. Mechanical properties of bitumen / Gorelyshev N.V., Akomova T.P. - 1968. — P. 81.

3. Bitumen and Its Modifier for Use in Pavement Engineering / M. Honarmand, J. Tanzadeh, M. Beiranvand // Sustainable Construction and Building MaterialsIntechOpen, 2019. https://doi.org/10.5772/intechopen.82489

4. Polymer Modified Bitumen / Tony McNally2011. — 424 p. 
5. Modern trends in the development of the construction industry in the production of building materials / A. Aldungarova, K. Aryngazin, V. Larichkin, A. Abisheva, K. Alibekova // Technobius. — 2021. — Vol. 1, No. 3. — P. 0003. https://doi.org/10.54355/tbus/1.3.2021.0003

6. Development of binder specification parameters based on characterization of damage behavior / T.P. Bahia HU, Zhai H, Zeng M, Hu Y // Journal of the Association of Asphalt Paving Technologists. — 2001. — Vol. 70. — P. 442470 .

7. Using Mineral Fibers to Improve Asphalt and Asphalt Mixture Behavior / L. Zhao, J. Chen, S. Wang // Traffic and Transportation Studies 2010. — Reston, VA: American Society of Civil Engineers, 2010. — P. 1352-1360. https://doi.org/10.1061/41123(383)129

8. Polymer modified asphalt binders / Y. Yildirim // Construction and Building Materials. — 2007. — Vol. 21 , No. 1. — P. 66-72. https://doi.org/10.1016/j.conbuildmat.2005.07.007

9. Polymer-Modified Asphalt Cements Used in the Road Construction Industry: Basic Principles / B. Brûlé // Transportation Research Record: Journal of the Transportation Research Board. — 1996. — Vol. 1535, No. 1. — P. 48-53. https://doi.org/10.1177/0361198196153500107

10. Oil refining / Eigenson A.S., Fryazinov V.V. - 1979. — P. 35.

11. Composition, structure and physical and mechanical properties of petroleum road bitumens / Ridenskaya I.M., Ridenskiyi I.V.// Bulletin of the Kharkov National Automobile and Road University. — 2017. — Vol. 79.

12. The Shell Bitumen Handbook / Robert N. Hunter, Andy Self and John Read2015. — 761 p.

13. Pavement design [Electronic resource] / Roadmasters — Access mode: http://roadmasters.ru/ukladkaasfalta/bazovye-momenty/konstrukciya-dorozhnoj-odezhdy.htm

14. Structure and properties of polymer-modified bitumens / Kalinina V.V. - 2002. - P. 65.

15. Binder for colored asphalt concrete / Barsukov A.N., Moskalev V.Yu., Pozdnyakova L.V., Kotlyarskiyi E.V. 2015. - Patent RU 2537596.

16. Information about Tetra Pak [Electronic resource] / Tetra Pak - Access mode: https://www.tetrapak.com/ru/abouttetra-pak

17. Features of the structure and properties of polymer-modified bitumens [Electronic resource] / Access mode: https://servisavtomatika.ru/articles/osobennosti-struktury-i-svoystv-bitumov-modificirovannyh-polimerami-164

18. ST RK 1374-2005 Bitumen and bituminous binders. Methods for determining the extensibility. — P. 33.

\section{Information about authors:}

Aigerim Syzdykova - Master Student, Department of Structural Engineering, L.N. Gumilyov Eurasian National University, Nur-Sultan, Kazakhstan, aigera090@mail.ru Aigul Zhakyp - Master Student, Department of Structural Engineering, L.N. Gumilyov Eurasian National University, Nur-Sultan, Kazakhstan, aigul.kairatkizi@mail.ru Assel Tulebekova - PhD, Assoc. Prof., Department of Structural Engineering, L.N. Gumilyov Eurasian National University, Nur-Sultan, Kazakhstan, krasavka5@mail.ru 